NBER WORKING PAPER SERIES

SECTORAL SHOCKS AND

STRUCTURAL UNEMPLOYMENT

Michael H. Riordan

Robert W. Staiger

Working Paper No. 2522

NATIONAL BUREAU OF ECONOMIC RESEARCH

1050 Massachusetts Avenue

Cambridge, MA 02138

February 1988

We have benefited from the comments of Edward Lazear, Joseph Stiglitz, Andrew Weiss, and seminar participants at the NBER Summer Institute, the Institute for International Economic Studies in Stockholm, and Bell Communications Research. The research reported here is part of the NBER's research program in International Studies. Any opinions. expressed are those of the authors and not thcse of the National Bureau of Economic Research. 
NBER Working Paper \#2522

February 1988

\title{
Sectoral Shocks and \\ Structural Unemployment
}

\begin{abstract}
When current effoloyers have more information about worker quaily than do potental employers, sectoral shocks cause structural

unemployment. That is, some workers laid off from an injured sector remain unemployed despite the fact hat they are of sufficient quality to be productively employed in an expanding sector at the prevailing wage...Moreover, sectoral unemployment rates are not monotonic in the severity of sectoral shocks due to the interaction of layof activty and hiring activity. Finaliy aquilionim empioyment decisions are not constraned pareto effloien, and can be improved by a polioy of adjustnert assistance.
\end{abstract}

Michael H. Riordan Department of Economics Stanford University stanford, CA 94305
Robert W. Staiger

Department of Economics Stanford University Stanford, CA 94305 


\section{Introduction}

Since Akerlof's (1970) seminal study of the sorting effects of prices in the used car market, the implications of adverse selection in the presence of informational asymetrles has been an actlve area of economic research. This is especially true with regard to the labor market, where informational asymmetries arise naturally between Individuals who know their productivity and firms who don't, or between current employers who have learned the quality of their workers and potential employers who remain uninformed. The former informational asymetry appears, for example, in Weiss (1980). who shows that 1 t can lead firms to make rigld wage offers accompanied by layoffs. The latter informational asymetry has been studied by Greenwald (1986), who examines its dampening effect on the interfirm moblifty of labor. Recently, several authors have emphaslzed the role of sectoral shocks which require the reallocation of an economy's product ive resources as an emplrically important source of unemployment (Lillen, 1982, Summers, 1986). Such structural unemployment makes sense on y in the presence of some form of "friction" in the labor market, which acts to diminish the intersectoral mobility of labor. Labor market informational asymetries represent one possible source of this friction.

We consider the informational asymmetry analyzed by Greenwald, but do so in a two sector model. 1 ' This allows us to explore the $1 \mathrm{mpl}$ lcations of asymmetric information in the presence of sectoral shocks, the existence of which give rise to a need for reallocation of 
the labor force across sectors. 21 We show that, when current employers have more information about worker quality than do potential employers, sectoral shocks glve rise to structural unemployment. That is, some workers laid off from the injured sector remain unemployed in equiliorium despite the fact that they are of sufficient quality to be productively employed somewhere in the economy at the prevaling wage. The source of this market fallure is the inability of potential employers to distinguish the abilities of workers within the pool of unemployed.

We also show that sectoral unemployment $r$ ates are not monotonic in the severity of sectoral shocks. For small shocks, unemployment increases in the injured sector and $f$ alls in the favored sector. However, for Iarger shocks these relationships are reversed due to the interaction of layof and hiring decisions. For larger shocks, firms in the declining sector layoff more, higher ability workers, which increases the average ability of the pool of unemployed in that sector. The quality effect induces firms in the favored sector to hire from that pool more aggressively, substituting these workers for marginal incumbent workers. This substitution reduces unemployment in the injured sector and raises it in the expanding sector.

Finaliy, we show that equiliorium employment decisions are not constrained pareto efficient. In making layoff decisions, firms in the infured sector 1gnore an important externality. The marginal retained worker has greater ability than the average laid-off worker. Thus if injured firms were to layof more, higher quality workers, this would 
increase the average quality of workers that relocate in the favored sector. Thus from an efficlency standpoint, even more layof s in the declining sector would be desirable. Adjustment assistance, in the form of a subsidy to workers leaving employment in the injured sector, internalizes this externality.

we explore these issues in the context of a small, two sector, two period, open economy subject to random terms of trade shocks. The model is developed in section. II. Section III characterizes the equilibrium adjustment of labor markets. Section IV characterizes unemployment rates as a function of terms of trade shocks, while section $V$ examines the efficiency role for trade adjustment asslstance. Section v conciudes.

\section{The Model}

Consider a small open economy with two sectors $(s=1,2)$ and two periods $(t=1,2)$. The economy is endowed with a continuum of workers with mass M. A worker is of uncertain quality $q$. The distribution of quality across the economy's workforce is described by the differentiable cumulative distribution function $H(q)$; let $n(q)=H^{\prime}(q)$. Define

$$
Z(q)=\int_{0}^{q} x d H(x) / H(q)
$$

$Z(q)$ is the average quality of that portion of the labor force which includes only workers of quality $q$ or below, $\bar{q} \equiv z(\infty)$ ig the 
(finite) population mean. Finally, we assume that $Z(q)$ is concave and $H(Q)$ has full support on the nonnegative real ine. The concavity of $z(q)$ will be used to ensure uniqueness of the equilibrium derived in the next section (see Remark 3).

For future reference define

$$
L(q)=\int_{a}^{\infty} x d H(x) .
$$

$M \cdot L(q)$ gives the economy"s effective labor force counting only workers of quality o or above.

Eirms are risk neutral and discount period 2 profits by the factor B. Each firm requires $k$ units of capital to operate; this investment is nondepreciating and irreversibie. $K=k \cdot N$ is the economy's exogenous total capital stock, and $N$ is the number of firms in the economy. Firms allocate themselves across sectors in period 1 so that the expected (two period) return to capital is the same in each sector. There is no entry or exit of firms in period 2 .

The two sectors are symmetric and thus have an equal number of firms in equilibrium. All firms share the same production function $f(\cdot)$ which gives a flrm's output as a function of its effective labor force. We assume that:

$$
f^{\prime}(\cdot)>0 ; f^{\prime \prime}(\cdot)<0 ; f^{\prime}(0)=\infty ; f^{\prime}(\infty)=0
$$

Goods prices are given each period by the rest of the world, and units are chosen so that the f1rst period price in each sector is unity. Second period prices are identically and independentiy 
distributed draws from a cumulative distribution function $C(P)$. We assume that $G(P)$ has full support on the nonnegative real ine.

Firms make period 1 labor hiring decisions with no information about individual worker quality. In response to relative price changes, firms then make period 2 labor hiring decisions knowing the quality of each of their own period 1 employees. However, no firm can observe directly the quality of workers it has not employed previously. As we show below, this period 2 informatlonal asymmetry can impede efficient intersectoral labor movements and lead to structural unemployment in the presence of terms of trade shocks.

The $y_{\mathbb{N}}$ firms in each sector make identical period 1 hiring and production decisions given a first period wage $W$. is determined in equilibrium by a (period 1) labor market clearing condition that we discuss later. For now we maintain the assumption of full employment in period 1 each firm employs m $\frac{M}{\mathrm{~N}}$ workers.

observing period 2 prices $P_{1}$ and $P_{2}$, each firm makes a period 2 employment decision. A firm knows only the ability of its incumbent workers. If it retains workers above quality $q$, then its effective retained labor force is $\mathrm{mL}(q)$; if a firm employs only incumbent workers above quality $q$ its output is $f(m L(q))$. We characterize labor market institutions as follows. After observing period 2 prices, a firm makes wage offers to incumbent workers, which they might either accept or reject. Different offers might be made to different workers; a worker is "laid off" if offered a wage below the opportunity wage. 
The reservation wage at which a worker is indifferent between working and not is determined by the expenditure function

$$
w_{0}=e\left(P_{1}, P_{2}\right) .
$$

All workers are assumed to have identical preferences and a common reservation utility level. 3 / We ignore period 1 saving by workers, so that period 2 utility depends only on period 2 prices and labor income. We also assume that each worker possesses a single indivisible unit of labor services (of varying quality) that might be either supplied or withneld from the labor market.

The expenditure function is linear homogenous, differentiable, increasing and concave in prices. We also assume that it is symmetric and satisfies a boundary condition; $e(1, p)=e(p, 1)$ and $e(1,0)=0$. Thus as $p\left(P_{2} / P_{1}\right)$ goes to zero $\left(w_{0} / P_{1}\right)$ goes to zero. The relevance of this will be made clear in the next section (see femark 1 ). Workers rejecting their wage offer from period 1 employers go to a sector-specific labor hiring hall. Knowing individual work history but not worker qualtity, firms can go to either labor hiring hall and hire new workers at a market clearing wage.

Several facts about equilibrium employment decisions are apparent from these assumptions. First, no labor is ever employed at a wage below the reservation wage $w_{0}$. Second, retained workers are paid the equilibrium wage in the labor hiring hall for their sector. Third, due to symmetry, firms never hire new workers from their own sector's hiring nal1. 4 / 


\section{Equilibrium Responses to Sectoral Shocks}

We now characterize period 2 equilibrium conditions for any period 2 relative price realization, assuming symmetric ful employment in period $t$ by the $\mathrm{y}_{\mathrm{N}}$ firms in each sector. The characterization is particularly simple for a second period relative price realization of unity, 1.e., in the absence of a second period terms of trade shock. This 13 because the quality composition of the labor hiring halis in the two sectors w1Il be identical in this case. Since firms never find quality in their own sector hiring halls sufflcient to generate hiring activity, and since in the absence of a second period terms of trade shock the quality composition of each hiring hall is the same, no hining will occur from either hall. Moreover, since retained workers are paid the equllibrium wage in the hiring hall for their sector, the economywide lack of hiring activity implies that all retained workers receive the reservation wage $w_{0}$.

Clearly for second period relative price realizations close to one, the quality composition of each sector's hiring hall will still be sufficlently similar to keep the hiring nalls lnactive, and retained workers will still be paid their reservation wage wo we now determine the range of second period relative prices for which this will be true. To this end, suppose that given the sectoral labor wage $w_{S}$ and goods price $P_{S}$ there were no hiring by sector $s$ firms of any new workers, 1.e, only incumbent workers were employed in sector $s$. Then each firm in sector $s$ would be willing to retain all new workers above 
quality $q_{5}$ satisfying the first order condition for profit maximization

(1) $P_{S} P\left(m L\left(q_{s}\right)\right) q_{s}=w_{s}$.

Equation (1) has a unique implicit solution

$$
q_{S}=Q\left(w_{S} / P_{S}, m\right)
$$

that is increasing in both arguments. Thus, without any intersectoral labor reallocation, worker retention decisions depend on a sectorspecific wage-price ratio (and a perlod i hiring decision.)

If labor hiring halls are inactlve, then workers in each sector are paid the reservation wage, i.e. $w_{S}=w_{0}$. Then the marginal retained worker in sector 1 is of quality

$$
q_{1}=Q\left(e\left(1, P_{2} / P_{1}\right), m\right)=Y\left(P_{2} / P_{1}, m\right)
$$

where use has been made of the linear homogeneity of the expenditure function. Sector 2 has a symmetric relationship $Q_{2}=Y\left(P_{1} / P_{2}, m\right)$. This function is increasing in both arguments. Moreover, $Y(0, m)=0$; as $\mathrm{P}_{2} / \mathrm{P}_{1}$ goes to zero sector 1 (the favored sector) retains all of its workers.

Define the function

$$
\Omega(p, m) \equiv Y(p, m) / Z(Y(1 / p, m)) .
$$


Thus, if $p=\left(P_{2} / P_{1}\right)$, then $\Omega(p, m)$ is the ratio of the quality of the marginal retained worker in sector 1 to the average quality of workers laid off in sector 2, assuming that labor hiring halls are not active.

Lema 1. $\Omega(p, m)$ is a continucus increasing punction of $P$. $\Omega(0, m)=0$ and $\Omega(1, m)>$. Thus given $m$ there exists a unique $p^{*}, 0<p^{*}<1$, such $\Omega\left(p^{*}, m\right)=1$.

Proof. Since $Y(p, m)$ is continuous and increasing in $p$ and $Z(q)$ is differentiable and increasing in $q, \Omega(p, m)$ must be continuous and increasing in p. $\Omega(0, m)=0$ follows from $e(1,0)=0$ while $\Omega(1, m)>1$ follows from the definition of $2(q)$

Remark $1 . e(1,0)=0$ assures that $p^{*}$ is well-defined.

otherwise, $\Omega(p, m)$ might exceed unity for all realizations of $p$, and equilibrium would never have any reallocation between sectors.

Labor hirlng halls w1ll be inactive and retalned workers paid their reservation wage in equilibrium whenever

$$
p^{*} \leq p^{/ p}, \leq 1 / p^{*}
$$

To see this, let $p=P_{2} / P_{1} \leq 1$, so that sector 1 is "favored" and sector 2 "injured." If retained workers are paid wo and hiring halis are inactive, then firms in sector 1 retain workers above $q_{1}=Y(p, m)$, while firms in sector two retain workers above 
$q_{2}=Y(1 / p, m)$. Moreover, $p \leq 1$ implies that $q_{1} \leq q_{2}$ and $z\left(q_{2}\right) \geq Z\left(q_{1}\right)$. If $p \geq p^{*}$ also, then $\varkappa(p) \geq 1$ implies $q_{1} \geq 2\left(q_{2}\right)$. Hence

$$
q_{2} \geq q_{1} \geq z\left(q_{2}\right) \geq z\left(q_{1}\right)
$$

and firms in neither sector have any incentive to hire a random worker irom either hiring hall at any wage above the reservation wage wo.

$$
\begin{aligned}
& \text { If, on the other hand, } p=p_{2} / p_{1}<p^{*} \text {, then } n(p)<1 \text { and } \\
& q_{2} \geq z\left(q_{2}\right)>q_{1} \geq z\left(q_{1}\right) ;
\end{aligned}
$$

Firms in sector 1 now have a strictly positive incentive to hire workers laid of from sector 2 ; otherwise the marginal retalned workers in sector 1 firm would be lower quality than average workers laid off in sector 2, and the expected profits of sector 1 firms could be increased by substituting the latter for the former at the reservation wage. 5 '

There are two cases to consider if $p=P_{2} / F_{1}<p^{*}$. In the first case, hiring halls clear at the reservation wage. In the second case, sector 1 firms have an excess demand for lald of sector 2 workers at the reservation wage, and the equilibrium sector 2 wage must rise to clear the market.

$$
\text { If } p=p_{2} / p_{1}<p^{*} \text { and all employed workers are paid the }
$$
reservation wage, then workers above $a_{2}=x(1 / p, m)$ are retained in the injured sector 2. Sector 1 firms retain only workers above quality $q_{q}$ $=Z\left(q_{2}\right)$ and demand $\psi$ additional workers from sector $2^{\prime}$ s hiring hall, where $H$ satisfies the first order condition for profit maximization. 


$$
P_{1} f^{\prime}\left(m L\left(z\left(q_{2}\right)\right)+\mu z\left(q_{2}\right)\right) \cdot z\left(q_{2}\right)=w_{0}
$$

Let $\phi(\cdot)=f^{-1}(\cdot)$ denote the inverse marginal product function. Then

$$
\begin{aligned}
\mu & =\left[\phi\left(e(1, p) / z\left(q_{2}\right)\right)-m L\left(z\left(q_{2}\right)\right)\right] / z\left(q_{2}\right) \\
& =D\left(e(1, p), z\left(q_{2}\right), m\right) .
\end{aligned}
$$

Define the excess demand function for labor in sector 2 's hiring hall by sector 1 firms hiring at the reservation wage as

$$
E(p)=D(e(1, p), Z(Y(1 / p, m)), m)-m H(Y(1 / p, m))
$$

We assume for convenience that $E(p)$ is decreasing in $p$ over the range $0<p<p^{*}, \underline{6}$. This assures that there is a unique $p$ less than $p^{*}$ such that excess demand is zero.

Lemma 2. There exists $p^{*}, \quad 0<p^{*}<p^{*}$, such that $E\left(p^{*}\right)=$ $0 . E(p)>0$ for $0 \leq p<p^{*}$, and $E(p)<0$ for $p^{*}<p \leq p^{*}$.

Proof. For $p=0$, we have that $e(1, p)=0$. Since $f(x)=0$, it follows that $\phi(0)=f^{-1}(0)=$ and thus that $D\left(e(1, p), Z\left(q_{2}\right), m\right)=\infty$. Therefore, $E(0)=\infty$. For $p=p^{*}$ it follows from $\Omega\left(p^{*}, m\right)=1$ that $\frac{e\left(1, p^{*}\right)}{z\left(q_{2}\right)}=f^{\prime}\left(m L\left(z\left(q_{2}\right)\right)\right)$ which implies in turn that $D\left(e\left(1, p^{*}\right), z\left(q_{2}\right), m\right)=0$... Thus, $E\left(p^{*}\right)<0$. The lemma then follows from the fact that $E(p)$ is continuous In $p$ and our assumption that $E(p)$ is decreasing in $p$ over the relevant range. 
Remark 2. If $E(p)$ were not decreasing in $p$ over the relevant range, there could exist disjoint intervals on which the inequalities stated in the lemma fail. However, $E(p)>0$ for $p$ sufficientiy close to zero and $E(p)<0$ for $p$ sufficientiy close to $p^{*}$.

Lemma 2 establishes that the sector 2 labor hiring hall is active and clears at the reservation wage if $p^{* *} \leq\left(P_{2} / P_{1}\right) \leq p^{*}$. If $0 \leq\left(P_{2} / P_{1}\right)<P^{* *}$. then there is an excess demand in this market at the reservation wage, and so the sector 2 wage must rise to clear the market. Workers in sector 2 will now be paid a wage $w_{>}>w_{0}$, and workers above $Q_{2}=Q\left(w / P_{2}, m\right)$ will be retained. All workers laid of $f$ from sector 2 are hired by sector 1 firms at the wage $w$. Firms in sector 1 retain workers above quallty $q_{1}$ at the reservation wage, where $q_{1}$ satisfies the first order condition for profit maximization

$$
f^{\prime}\left(m\left[\bar{q}-L\left(q_{2}\right)+L\left(q_{1}\right)\right]\right) q_{1}=e(1, p)
$$

Finally, market clearing for the sector 2 labor market requires

$$
f^{\prime}\left(m\left[\bar{q}-L\left(q_{2}\right)+L\left(q_{1}\right)\right]\right) Z\left(q_{2}\right)=w / P_{1},
$$

which, using (3), implies that

$$
\frac{w}{P_{2} z\left(q_{2}\right)}=\frac{e\left(1 / p_{1} 1\right)}{q_{1}} .
$$


(4) $f^{\prime}\left(m L\left(q_{2}\right)\right) q_{2}=w / P_{2}$

yields

(5) $f^{\prime}\left(m L\left(q_{2}\right)\right) q_{2} / z\left(q_{2}\right)=e(1 / p, 1) / q_{1}$.

Lemma 3. For a given value of $p, 0<p<p^{*}$, equations (3), (4) and (5) have a unlque solution in $q_{1}, q_{2}$, and $w / p_{2}$.

Proof. Equation (3) establishes a monotonically increasing relationship between $q_{1}$ and $q_{2} \cdot$ Equation (5) establishes a decreasing relationship, with $q_{1}$ going to zero as $q_{2}$ goes to infinity, and $q_{2}$ going to zero as $q_{1}$ goes to infinity. Thus equations (3) and (5) have a unique solution in $q_{1}$ and $q_{2}$, with $w / P_{2}$ determined by equation (4).

Remark 3. The concavity of $2(9)$ establishes a monotonic relationship between $q_{1}$ and $q_{2}$ in equation (5), which establishes uniqueness but is unnecessary for existence. By selecting the equilibrium with the lowest value of $w / p_{2}$, the assumption can be dropped.

It may seem paradoxical that workers from the injured sector might be paid a higher wage, but there is a natural intuition for this. Our assumed labor market institutions inply that workers in each sector are paid their opportunity wage, which is determined in part by the average quality of the stock of workers laid of from that sector. Layof fs are 
greater in the injured sector, and since layoffs are ordered by quality, the average guality of laid of workers in that sector is greater. Thus, if demand for labor in the favored sector is sufficientiy great, the wage for workers in the injured sector can be higher.

This provides a complete characterization of period 2 equiliorium when sector 2 is the injured sector, i.e. $P_{1} \geq P_{2}$. Relationships are symmetric when sector 1 is injured. We summarize these results in the following proposition.

Proposition 1. Let $p=\left(P_{2} / P_{1}\right)$ and $p^{*}$ satisfy $\Omega\left(p^{*}\right)=1$. Then $p^{*}<1$ and there exists $p^{* *}, 0<p^{* *}<p^{*}$, such that: (a) If $p^{*} \leq p \leq 1 / p^{*}$, then labor hiring halls are not active and retained workers in both sectors are paid the reservation wage.

(b) If $p^{*} \leq p<p^{*}$ or $1 / p^{*}<p \leq 1 / p^{* *}$, then the favored sector hires workers laid off from the injured sector and all employed workers are paid the reservation wage. (c) If $0 \leq p<p^{* *}$ or $p>1 / p^{* *}$, then the favored sector hires all workers Iald off from the injured sector, retained workers in the favored sector are pald the reservation wage, and all workers previously employed in the injured sector are paid a wage above the reservation wage.

To close the model, we describe equilibrium in period 1 . Since 
the relevant technical conditions are cumbersome and not particularly enlightening we do so cursorily. With superseripts $d$ and $f$ denoting the injured and favored sector, respectively, second period profits in the two sectors are given by

$$
\Pi^{d}\left(p^{d}, w^{d}, q^{d}, m\right)=p^{d} f(m L(q))-w^{d} m\left[1-H\left(q^{d}\right)\right]
$$

and

$$
\begin{aligned}
\Pi^{f}\left(p^{f}, w^{f}, w^{d}, q^{f}, q^{d}, \mu, m\right) & =p^{f} f\left(m L\left(q^{f}\right)+\mu z\left(q^{d}\right)\right) \\
& -w^{f} m\left[1-H\left(q^{f}\right)\right]-w^{d} u
\end{aligned}
$$

where $q^{f}, q^{d}$, and $\mathcal{L}$ are chosen by profit maximizers and $w^{f}$ and wd clear labor markets as determined above. The period 1 wage is then given by the labor market clearing condition

$H=f^{\prime}(m \bar{q}) \vec{q}+B \int\left\{\int P_{1} \geq P_{2} \frac{\partial \Pi^{f}(\cdot)}{\partial m} d G\left(P_{2}\right)+\int P_{2} \geq P_{1} \frac{\partial \pi^{d}(\cdot)}{\partial m} d G\left(P_{2}\right)\right\} d G\left(P_{1}\right)$

By the envelope theorem, the right hand side of this expression is just the discounted two perfod marginal revenue product of labor with symmetric first period full employment.

To have labor fully employed in the first period, $w$ must be above the period 1 reservation wage $w_{0}$. This will be the case provided that the size of the labor force $M$ and the discount factor $B$ are not "too large."I' Einally, positive discounted expected profits will accrue as a rent to the owners of capital. 


\section{Unemploywent}

In this section we describe the nature of the unempioyment that arises in the second period of the model, and show that structural unemployment can result from a terms of trade shock. We take structural unemployment to refer to the situation in which a portion of the workers laid off from the injured sector remain unemployed in equilibrium despite the fact that they are of sufficient quality to be productively employed somewhere in the economy at the reservation wage.

Suppose that sector 1 is the favored sector and sector 2 is the injured sector; $p=\left(P_{2} / P_{1}\right) \leq 1$. Define the sectoral effective unemployment rate in the second period as the fraction of a sector's first period effective labor force that does not find employment somewhere in the economy in period 2. $8 /$ The period 1 effective labor force in each sector is $\frac{M}{2} \cdot \bar{Q}$, with $\bar{Q}=L(0)$. Thus the period 2 effective unemployment rate in the favored sector 1 is

$$
U_{1}=1-L\left(q_{1}\right) / L(0)
$$

where $q_{1}$ is the marginal retained worker in sector 1. Matters are a bit more complicated for the injured sector, since some of the workers laid off from this sector might be rehired in sector 1; the effective unemployment rate for sector 2 is

$$
u_{2}=1-\left[L\left(q_{2}\right)-\left(\mu Z\left(q_{2}\right) / m\right)\right] / L(0)
$$

$q_{2}$ is the marginal worker retained in sector 2 , and $\mu Z\left(q_{2}\right)$ is the amount of effective labor per firm that is laid off in sector 2 and 
rehired in sector 1 . The values of $q_{1}, q_{2}$, and $\mu$ depend on the terms of trade shock p, as described in the previous section.

To see how effective unemployment rates depend on the terms of trade shock, consider first the case with the second period relative price remaining at its first period value; $p=1$. Then $q_{1}=q_{2}=$ $Y(1, m)$ and

$$
U_{1}=U_{2}=1-L(Y(1, m)) / \vec{q}_{n}=U_{n}
$$

$U_{n}$ is the "natural" rate of unemployment in each sector. It's level reflects only the underlying quality composition of the labor force. Moreover, since the marginal product of labor is equated across sectors, and is equal to the reservation wage, labor is allocated efficientiy. Hence the natural rate of unemployment is not structural in nature. Next, suppose that $p<1$ and consider the favored sector, sector 1. Erom our previous analysis we know that no worker laid of in the favored sector is ever rehired by the injured sector. However, this unemployment is not structural, because the marginal worker latd off in sector 1 is of lower quality than tie marginal worker retained in sector 2 ; i.e. $a_{1} \leq q_{2}$. Since the marginal productivity of a $q_{1}$ worker in sector 1 is just equal to the reservation wage, and the marginal productivity of that worker in sector 2 is lower, it follows that no worker laid off in sector 1 can be productively employed anywhere in the economy. Thus, if structural unemployment exists it must be found in the injured sector 2 . 
Suppose that $i>p \geq p^{*}$, so that the terms of trade shock is "small". Then from Proposition $i \mu=0$, and unemployment in the injured sector is

$$
U_{2}=1-L\left(Q_{2}\right) / L(0)
$$

There is no hiring hall activity, and $a_{2}=y(1 / p, m)$. For prices in this range, unemployment in the injured sector rises above the natural rate (1.e. $\left.U_{2}>U_{n}\right)$, and the amount of effectlve unemployment is increasing in the size of the shock. Conversely, unemployment in the favored sector is below the natural rate and is decreasing in the size of the shock.

Moreover, for relative prices in this range, some of the unemployment in the injured sector is structural. A portion of workers laid off in sector $z$ are of sufficient quality to be productively employed in sector 1 . This follows from $a_{2}>a_{1}$. The marginal product of retained workers in sector 1 is equated to the reservation wage. However, the marginal retained worker in sector 2 is of higher quality than the marginal retained worker in sector 1 , and therefore would have a strictly higher marginal product if employed in sector 1.

Nevertheless, none of the high quality workers laid off in the injured sector are picked up by firms in the favored sector. High quality laid of workers are unable to distinguish themselves from others in the injured sector's unemployment pool. The average quality of these unemployed workers is not sufficient to generate any hiring interest by favored sector firms; 1.e. $z\left(q_{2}\right)<q_{1}$. Thus structural 
unemployment is an equilibrium phenomenon in sector 2 for relative price shocks in the range $1>p \geq p^{*}$.

Consider next the behavior of unemployment rates for larger terms of trade shocks characterized by second period relative prices that satisfy $p^{*}>p \geq p^{*}$. In this case, each firm in the favored sector employs

$$
\mu \equiv\left[\phi\left(e(1, p) / z\left(q_{2}\right)\right)-m L\left(z\left(q_{2}\right)\right)\right] / z\left(q_{2}\right)
$$

units of labor from the hiring hall of the injured sector. The corresponding effective unemployment rate in the injured sector is

$$
U_{2}=1-\left[L\left(a_{2}\right)+L Z\left(q_{2}\right) / m\right] / L(0)
$$

The qualitative behavior of this measure of unemployment depends on two effects.

Since sector 2 firms do not hire any new workers from labor hiring halls, $q_{2}=Y(1 / p, m)$ is the marginal retained worker in the injured sector. Thus the fraction of workers retained in sector 2 , $L\left(q_{2}\right) / L(0)$, is Increasing in $p$. However, the fraction of laid-off sector 2 effective workers that are rehired by sector 1 , $\mu Z\left(q_{2}\right) / m L(0)$, Is decreasing in $p \cdot \frac{9}{}$ Depending on the relative strengths of these two effects, the sector 2 unemployment rate, $U_{2}$, may not be monotonic in $p$ over the range $p^{*}>p \geq p^{*}$. Nevertheless, as $p$ goes to $p^{* *}$, if goes to $\mathrm{mH}^{*}\left(q_{2}\right)$ and therefore $U_{2}$ must go to zero. Consequently, $U_{2}$ must be increasing with $p$ in this range that are sufficiently close to $p^{* *}$. 
Note, however, that structural unemployment persists in the injured sector as long as $\mathrm{U}_{2}>0$, since the quality composition in the sector 2 hiring halls is unaffected by the hiring activity of sector 1 firms. Since sector 1 firms cannot directly observe the quality of an individual worker, these firms must hire new workers arbitrarily. Since $q_{2}>q_{1}$, there will remain workers in sector $2^{\prime}$ s unemployment pool who could be productively employed in sector 1 at the reservation. wage, but who are not. Thus structural unemployment persists untiI $U_{2}$ is driven to zero.

Paradoxically, unemployment in the favored sector 1 is also nonmonotonic in the size of the shock. That is, unemployment may increase in sector 1 even as conditions improve in that sector. This phenomenon occur for relative price realizations in the interval $p^{*} \leq p<p^{*}$. In this case, sector 1 firms rehire a positive quantity of labor from sector 2, although some unemployment remains in the injured sector whose labor hiring hall is clearing at the reservation wage. The corresponding optimal retention rule for sector 1 firms is to equate the marginal quality of retained workers to the average quality of new workers; $q_{1}=z\left(q_{2}\right)$. Since $z\left(q_{2}\right)$ is increasing in the size of the shock (as better quality workers are laid of from sector 2), so must be $q_{1}$, and unemployment in sector 1 must rise. Finally, consider very large terms of trade shocks for which $0<p<p^{* *}$. In this case $\mu=m H\left(q_{2}\right)$; laid of workers in sector 2 are fully rehired by firms in sector 1 . Thus the effective unemployment rate in the injured sector is zero. On the other hand, the optimal 
retention decision for sector 1 is still to equate the marginal nevenie product of incumbent workers to the reservation wage. Unemployment in sector $\%$ persists, even though it must vanish in the imit as $p$ zoes to zero. This follows from our assumption that the distribution of labor quality has full support on the positive real line. Thus there exist very low quality workers who are unproductive in sector i for any positive price realization. Moreover, these laid off workers from sector 1 are not rehired in sector 2 where they are even less productive.

Eigure 1 summarizes this discussion by depicting $U_{1}$ and $U_{2}$ as functions of $P=P_{2} / P_{1}$. As described above, $U_{1}=U_{2}=U_{n}$ at $p=1$, and there is no structural unemployment. For $1>p \geq p^{*}$, effective unemployment decilnes monotonicaliy in the favored sector 1 and increases monotontcaliy in the injured sector 2. For $p^{*}>p \geq p^{*}$, sector 1 firms substitute labor from the sector 2 niring hall for their own marginal workers; $U_{1}$ rises, while $U_{2}$ eventually falis reaching zero at $p^{*}$. Einally, for $0<p<p^{*}, U_{2}$ remains at

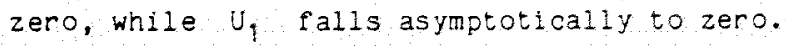

An Inverse mirror image of these patterns characterizes unemployment rates in the converse case where $p>1$ and sector 2 is the favored sector. Finaliy, note that structural unemployment, as defined above, exists at any price realization different from unity that leaves a positive unemployment rate in the injured sector. Ne summarize these results. 
Proposition 2. A second period terms of trade shock leads to structural unemployment unless the shock is sufficientiy large to eliminate unemployment altogether in the injured sector. Moreover, sectoral unemployment rates are not in general monotonic in the size of the shock.

\section{Adjustment Assistance}

In this section we explore the possbility of welfare improving government intervention. In particular, we examine the effects of a government program to assist workers in moving from the injured to the favored sector in the second period. The adjustment assistance is assumed to take the form of an "exil subsidy" offered to any worker who is willing to leave the injured sector and search for work elsewhere in the economy, i.e. go to the labor hiring hall.

As noted in section II the first period of the model is characterized by full employment, with labor (and capital) symmetrically allocated across sectors. Since the second period adjustment assistance program will, ex ante, have symmetric effects on second period profits In the two sectors, it will not effect the sectoral allocation in the first period of either capital or labor (though the first period wage will be affected) and thus wil leave unaltered the first period output levels and full employment condition that prevail absent intervention. As such, assuming that lump sum instruments are available for redistribution, ary changes in welfare brought about by the adjustment program will be found in the second period. 
In the presence of I ump sum redistributive instruments, second period welfare is measured by the value of production, measured at world prices, plus the value of unemployed labor, measured at the reservation wage. Assume as before that sector 1 is the relatively favored sector; $p=p_{2} / P_{1}<1_{0} \quad$ Employment decisions determine the marginal retained worker in each sector $q_{1}$ and $\left.q_{2}\right)$ and the amount of labor reallocated from sector 2 to sector 1 ( $\omega)$. Constrained Pareto efficient employment decisions solve the program:

$$
\begin{aligned}
& \operatorname{Max} P_{1} f\left(m L\left(q_{1}\right)+\mu Z\left(q_{2}\right)\right)+P_{2} f\left(m L\left(q_{2}\right)\right)+m w_{0}\left[H\left(q_{1}\right)+H\left(q_{2}\right)-\mu / m\right] \\
& q_{1}, q_{2}, \mu \\
& \text { subject to } m{ }^{\prime}\left(q_{2}\right) \geq \mu \geq 0 .
\end{aligned}
$$$$
\text { This definition of constrained efficiency presumes that the }
$$
- Lanner also cannot identify the ability of laid of workers. Consequently, structural unemployment is consistent with this notion of constrained efflolency. In this sense, structural unemployment might be viewed as an inevitable consequence if asymmetrie information about workers' abilities, and the absence of institutions to communicate that information. In principle a planner could gain information on worker's ability by receiving communications from sector 1 firms, who have a weak incentive to be truthful, and do even better (Harris and Townsend 1981, Holmstrom and Myerson 1983). We shall show that without intervention equilibrium employment decisions fall our stricter definition of 
constrained efficiency for sufficiently large shocks, but that a policy of adjustment assistance can rectify this.

Constrained efficiency requires that (favored) sector i firms equate the marginal revenue product of the marginal retained worker to the resevation wage;

(6) $p_{1} f\left(m L\left(q_{1}\right)+u Z\left(q_{2}\right)\right) q_{1}=w_{0}$

If $u>0$, so that some labor is reallocated from the injured to the favored sector, then the marginal revenue product of the average realiocated worker must be greater than or equal to the reservation hage;

$$
P_{1} f^{\prime}\left(m L\left(q_{1}\right)+\mu Z\left(q_{2}\right)\right) Z\left(q_{2}\right) \geq W_{0}
$$

If $m H\left(q_{2}\right)>\mu>0$, so that some but not all laid of 1 abor from the injured sector is reallocated to the favored sector, then relation ( 7 ) must nold with equality.

Finally, a necessary condition for an optimal retention decision in (the injured) sector 2 is

(8) $P_{2} f^{\prime}\left(m L\left(q_{2}\right)\right) q_{2}=(1-\theta) w_{0}+\theta p f^{\prime}\left(m L\left(z\left(q_{2}\right)\right)+\mu z\left(q_{2}\right)\right) q_{2}$ where $\theta=\mu / m H\left(q_{2}\right)$ is the fraction of laid off sector 2 firms hired in sector 1. This condition is derived by combining the first order conditions for optimal $\mu$ and $q_{2}$. Its interpretation is that the marginal revenue product of a marginal retained worker in the injured sector should be equal to a welghted average of the reservation wage and 
his marginal mevenue product in the favored sector. This weighting reflects the fact that the laid off worker will be remployed with some probability.

When $i>p \geq p^{*}$ it is straightforward to show that the equilibrium employmert decisions are constrained efficient. In equilibrium, each firm equates the marginal revenue product of the marginal retained worker to the reservation wage, which is a necessary condition for welfare maximization given that $u=0$. Moreover. $\mu=0$ is optimal because, at these prices, $q_{1}>z\left(q_{2}\right)$ implies that the marginal revenue product of the average laid of worker in the injured sector is below the reservation wage.

The more interesting case is when $p^{*}>p$ and at least some laid of workers are reemployed in equilibrium; $\mu>0$. At the equilibrium corresponding to these prices, condition (6) holds and condition (7) holds, but condition ( 8 ) fails. To see this, recall that in equilibrium, the marginal revenue products of the marginal retained worker in sector 2 , and of the average new worker in sector 1 , are each equated to market clearing wage for sector 2 's labor hiring hall (w). Moreover, this wage is equal to the reservation wage ( $\left.w_{0}\right)$, unless unemployment 19 zero in sector 2 , in which case $\theta=1$. Since $a_{2}$ > $z\left(q_{2}\right)$, it follows that

$$
\begin{aligned}
P_{2} f^{\prime}\left(m L\left(q_{2}\right)\right) q_{2} & =w \\
& =(1-\theta) w_{0}+\theta w \\
& =(1-\theta) w_{0}+\theta P_{1} f^{\prime}\left(m L\left(q_{1}\right)-\mu Z\left(q_{2}\right)\right) Z\left(q_{2}\right) \\
& <(1-\theta) w_{0}+\theta P_{1} f^{\prime}\left(m L\left(q_{2}\right)+\mu Z\left(q_{2}\right)\right) q_{2}
\end{aligned}
$$


Thus condition (8) fails in equilibrium when $p<p^{*}$. Too few workers are laid of from the injured sector!

This surprising result has a straightforward intuition. Equiliorium layof decisions are profit-maximizing. However, when $p^{*}>$ p. there is an externality to layof decisions which sector 2 firms ignore. Laying off more, higher quality, workers increases the average quality of the pool of unemployed, which increases the average quality of new workers nired in sector one. At the margin, the loss of profits in sector 2 are of second order importance, while the gain in profits in sector 1 is of first order importance. Thus total welfare goes up. We next show that an exit subsidy to workers in the injured sector can achieve constrained efficiency. Suppose that all workers leaving jobs in the injured sector 2 are paid a subsidy $S$. The wage to petained workers in that sector must be raised by the full amount of the subsidy to induce then to stay. Consequently, firms in the injured sector will be induced to layof more workers, maximizing profits by equating the marginal revenue product of the marginal retained worker to the market-clearing wage in the labor hiring hald plus the subsidy. other equilibrium conditions are as before. Therefore,

$$
\begin{aligned}
P_{2^{\prime}} f^{\prime}\left(m L\left(a_{2}\right)\right) & =w+S \\
& =(1-\theta) w_{0}+\theta w+s \\
& =(1-\theta) w_{0}+\theta q_{1} f^{\prime}\left(m L\left(q_{1}\right)+\mu z\left(a_{2}\right)\right) Z\left(a_{2}\right)+s .
\end{aligned}
$$

Comparing this condition with condition (8), the optimal subsidy satisfies 


$$
S=o P_{1} \cdot\left(m L\left(q_{2}\right)+\mu z\left(q_{2}\right)\right) z\left(q_{2}\right)\left[q_{2}-z\left(q_{2}\right)\right]
$$

which is strictly positive for $0>0$. The optimal exit subsidy is Pareto improving if it is combined with appropriate lump sum transfer payments. $10 \%$

This discussion is sumarized by the following proposition.

Proposition 3. A policy of adjustment assistance is warranted on efficiency grounds whenever the second period terms of trade shock is of sufficient magnitude to induce some labor reallocation from the injured to the favored sector.

\section{Conclusion}

We have attempted to explore how an economy responds to a terms of trade shock when current employers know more about the qual ity of their workers than do potential employers located in another sector. Three main results emerge from our anaiysis. Eirst, in such an economy, sectoral shocks give rise to a situation in which mary of those laid off from injured sector firms fall to find employment elsewhere in the economy, despite the fact that the value of their marginal product in the favored sector would be greater than the prevailing wage. We define this as structural unemployment. Second, due to the interaction of layof and hiring decisions, sectoral unemployment $r$ ates are not monotonic in the size of sectoral shocks. Third, if the sectoral shock is of sufficient magnitude, a case can be made on efficiency grounds for providing adjustment assistance to workers leaving the injured sector. 
The simple model we have developed can be extended in several directions, to which we believe these basic results are robust. We mention here some of the potentially more interesting possibilities. Greenwald's (1986) anaiysis suggests a couple of natural extensions. The first concerns our modeling of labor markets. We have modeled iabor market institutions in a way that rules out raiding by assumption. However, our set up is formally equivalent to the "offer matching" assumption employed by Greemald and by Milgrom and oster (1987) In which raids do not occur in equilionlum. A model in which raids can ocour in equilibrlum is that of Lazear (1985) due to firmspecific quality attributes. In his set up, it is the higher quality workers that gain interfirm mobility as a result of raids. As such, the possibility of such raids is unikely to alter in a fundamental way the nature of the structural unemployment that arises in our model, which ocours at the low end of the quality spectrum.

We could also introduce random guits as in Greenwald and Giboons and Katz (1987). This would capture the idea that workers leave jobs for other exogenous reasons. The addition of randon quits would facilfate sectoral mobility, by increasing the average quality of the pool of unemployed in each sector, but would not resolve the fundamental adverse seiection problem that gives rise to our resuits. in fact, by promoting intersectoral hiring activity, random quits would increase the range of price shocks for which adjustment assistance is warranted. Gibbons and Katz extend the creenwald model to two sectors, but assume technological differences between sectors which make one sector 
sensitive to labor quality differences and the other not. While the authors explore the intersectoral wage and mobility predictions of the model in the presence of random quits, one could presumably study how such an economy responds to sectoral snocks as well.

A third period could aiso be added to our model. This would complicate the model considerably, since the retention decision of firms in period 2 would provide publicly available information about worker quality in period 3. However, as in Greenwald's model, the addition of a third period is likely to intensify the problem of adverse selection in this model, reducing further the level of intersectoral labor mobility and, as such, exacerbating the degree of structural unemployment and pushing the economy further away from its constrained Pareto optimum.

The role of contracts might also be considered. Our analysis has relied on the implicit assumption that employers cannot make credible long-term commitments to workers. However, allowing long-term bilateral contracts between a firm and employees would not alter the information asymmetry between sectors which is at the heart of our results. In fact contracts might further diminish intersectoral mobility due to insurance provided to workers. On the other hand, in a multiperiod extension of our model, contracts might in some circumstances facilitate intersectoral mobility by enabling workers of different abilities to selp-select.

Finally, we note that our analysis might have some 1 mpllotions for empirlcal methodology. For example, Lillien (1982) estimates a 
Ihear relationship between unemployment and a measure of sectoral shifts. The implicit underlying hypotheses is that greater sectoral shocks result in more layofis. However, our analysis suggests that sectoral unemployment rates are not generaliy monotonic in sectoral shocks. Thus a more flexible functional form might be more appropriate for estimation. 


\section{Footnotes}

11 See Rogerson (1987) for a two-sector model based on costly search. 2 In Greenwald's one-sector model, workers change irms because of random quit behavion. Absent these random quits, there would be no interfirm labor movement, and no need for it from the standpoint of economic efficiency. We briefly discuss random quits in our concluding section.

3/ Implicitly, we are assuming that there is a third sector, which might be thought of as "nome production," and with which this reservation utility is associated.

4/ We have modeled labor market institutions in a way that rules out raiding of retained workers by outside firms. Eormally, our set up is equivalent to the "of fer matching" assumption of Greenwald $(1986)$

5/ Here we make use of the fact that we are working with a continuum of workers implying a "large numbers" property (Judd, 1985). Otherwise the concavity of the production function would induce "risk aversion" in hiring new workers.

Ef E(p) w11l always be decreasing in $p$ if $\mathrm{f}^{\prime}(\cdot)$ is small in absolute value relat ve to $f^{\prime}(\cdot)$

7 Given that the rest of the population chooses to work in period. a worker who chooses to work in period 1 receives the first period wage $W$, while a worker who chooses to remain unemployed recelves the first perlod reservation wage $e(1,1)$. In the second period, a worker who was previously employed say, in sector 2 , will 
receive the wage $w^{d}$ with probability $p$ and the second period reservation wage $w^{0}$ with probability $(1-p)$, where $p$ is the probability that $p<p^{*}$. If the worker chooses not to work in the first period, he then erters period 2 thought to be the population mean quality $\bar{q}$. Since second period equilibrium requipes that $\frac{f}{q}=\frac{w^{d}}{Z\left(q^{d}\right)}>\frac{w^{d}}{q^{d}}$, such a worker would choose to locate in the favored sector and receive $\frac{w^{f}}{q} \bar{q}$. Thus, the worker Will choose to work in pericd i if $w-e(1,1)>B\left[\frac{f}{q} \bar{q}-\left(p w+(1-p) w^{0}\right)\right]$, which holds if $b$ and $M$ are not too large.

8/ It is convenient to work with units of effective rather than actual unemployment, though the two measures respond to terms of trade shocks in a qual itatively similar fashion.

9 This follows from the fact that the effective wage-price ratio for sector $1, e(1, p) / Z(Y(1 / p, m))$, is increasing in $p$.

10/ These results regarding constrained inefficiency and the avaliability of welfare improving tax instruments are an application of a more general analysis in Greenwald and stiglitz $(1986)$. 


\section{References}

Akerlof, George (1970), "The Market for 'Lemons': Qualitative uncertain. and the Market Mechanism," Quarterly Journal of Economics, 84, pp. 288-300.

Gibbons, Robert and Lawrence Katz, "Learning, Mobility, and InterIndustry wage Differences, unpublished manuscript, July 1987 .

Greenwald, Bruce G. (1986), "Adverse Selection in the Labor Market," Review of Economic Studies, 53, pp. 325-347.

Greenwald, Bruce G, and Joseph E. Stiglitz, "Externalities in Economies with Imperfect Information and. Incomplete Markets," Quarter1y Journal of Economics, May 1986, pp. 229-264.

Harris, Milton and Robert M. Townsend (1981), "Resource Allocation under Asymetric Information," Econometrica, 49, pp. 33-64.

Holmstrom, Bengt and Roger B. Myerson (1983), "Efficient and Durable Decision Rules with Incomplete Information," Econometrica, $51, \mathrm{pp}$. 1799-1820.

Judd, Kenneth, "The Law of Large Numbers with a Continuum of IID Random Variables," Journal of Economic Theory, 1985, vol. 35, pp. 19-25.

Lazear, Edward ?., "Raids and of fer-Matoning," manusoript, March 1985.

Lilien, David M. (1982), "Sectoral Shifts and Cyclical Unemployment," Journal of Political Economy, 90, pp. $777-993$.

Milgrom, Paul and Sharon Oster, "Job Oiscrimination, Market Eorces, and the Inyisibility Hypothesis," Quarterly Journal of Economics, August $1987, \mathrm{pp} .453-476$.

Rogerson, Richard (1987), "An Equilibrium Model of Sectoral Reallocation," Journal of Political Economy, 95, pp. $824-834$.

Summers, Lawrence $H$. (1986), "Why is the Unemployment Rate So Very High Near Full Employment." Brookings Papers on Economic Actlvity, 2, pp. $339-383$.

Weiss, Andrew (1980), "Job Queues in Labor Markets with Flexible Wages," Journal of Political Econony, 88, pp. 526-558. 
Figure 1

EERECTIVE UNEMLLOYMNT RATES

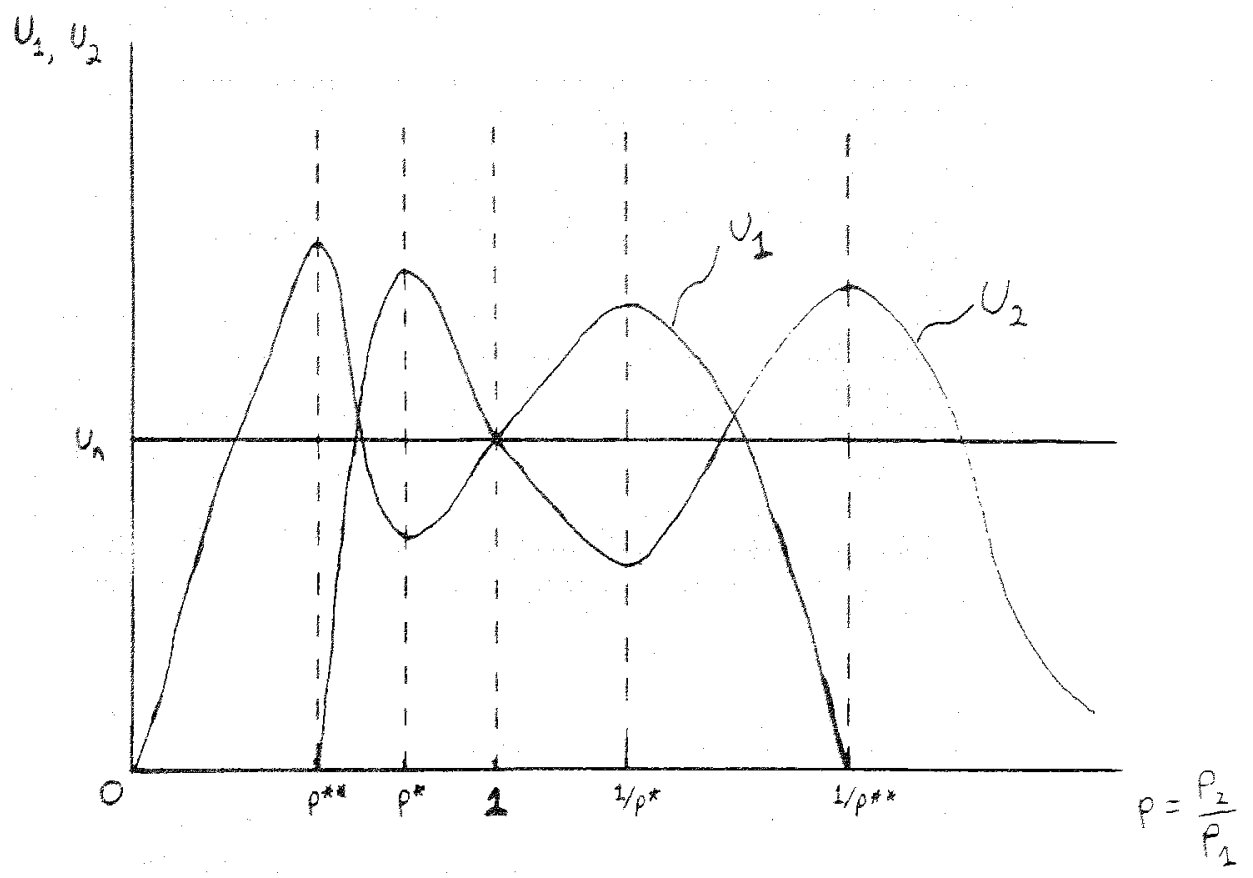

